Review

\title{
Development of Cell-Specific Targeting Systems for Drugs and Genes
}

\author{
Makiya NishiKaWA \\ Department of Biopharmaceutics and Drug Metabolism, Graduate School of Pharmaceutical Sciences, \\ Kyoto University; Sakyo-ku, Kyoto 606-8501, Japan. \\ Received September 3, 2004
}

\begin{abstract}
Cell-specific targeting systems for drugs and genes have been developed by using glycosylated macromolecule as a vehicle that can be selectively recognized by carbohydrate receptors. Pharmacokinetic analyses of the tissue distribution of glycosylated proteins came to the conclusion that the surface density of the sugar moiety on the protein derivative largely determines the binding affinity for the receptors and plasma lectin. Many glycosylated delivery systems have been developed and their usefulness investigated in various settings. Galactosylated polymers, when properly designed, were found to be effective in delivering prostaglandin $E_{1}$ and other low-molecular-weight drugs selectively to hepatocytes. In addition, glycosylated superoxide dismutase and catalase were successfully developed with minimal loss of enzymatic activity. A simultaneous targeting of these two enzymes to liver nonparenchymal cells significantly prevented hepatic ischemia/reperfusion injury. On the other hand, galactosylated catalase, a derivative selectively delivered to hepatocytes, effectively inhibited hepatic metastasis of colon carcinoma cells in mice. Finally, hepatocyte-targeted in vivo gene transfer was achieved by synthesizing a multi-functional carrier molecule, which condenses plasmid DNA, delivering DNA to hepatocytes through recognition by asialoglycoprotein receptors, and releasing DNA from endosomes/lysosomes into cytoplasm.
\end{abstract}

Key words receptor-mediated endocytosis; pharmacokinetics; tissue distribution; asialoglycoprotein receptor; reactive oxygen species; gene delivery

The completion of the Human Genome Project allows drug candidates to be screened based on their interactions with target protein. Analysis of aberrant profiles of protein expression in disease states has led to the development and marketing of drugs able to interact with specific molecular targets. These compounds can be highly specific and effective, because they have a degree of specificity as far as their pharmacological activity is concerned. However, they still induce significant side effects and a number of adverse responses have been reported. Not only low-molecular-weight chemical compounds but also proteins, which could exhibit beneficial effects in certain diseases, have become candidate therapeutic agents to treat inherited and acquired diseases. However, most proteins examined thus far have had serious problems associated with their pharmacokinetic properties.

Targeted delivery of these drug candidates to the site of action is one solution for increasing their therapeutic index, irrespective of their specific pharmacological activity. Since Ringsdorf first proposed a model for a water-soluble macromolecular prodrug, ${ }^{1)}$ targeted delivery of anticancer drugs, biologically active proteins, antisense oligonucleotides and genes has been examined in great detail in an attempt to achieve an improved therapeutic output. In addition, the development of monoclonal antibodies as well as the finding of numbers of receptors on the cellular surface have made it possible for researchers to use such molecules involved in specific recognition as natural glycoproteins for the targetspecific delivery of pharmacologically active compounds. Of the many combinations investigated, the sugar-lectin interaction has several features that are appropriate for the cell-specific targeting of pharmaceuticals; (i) the expression of lectins is specific to some types of cells, (ii) the affinity of ligands can be high enough for in vivo targeting, and (iii) the use of the recognition system produces little interference with the interactions that are important for life. Asialoglycoprotein receptors on hepatocytes and mannose receptors on several macrophages like Kupffer cells and liver sinusoidal endothelial cells recognize the corresponding sugars on the non-reducing terminal of sugar chains. ${ }^{2)}$ The use of sugar moieties for receptor-mediated drug targeting started with the pioneering work by Rogers and Kornfeld in $1971,{ }^{3)}$ and a number of applications have been reported with antiviral drugs, antitumor agents, diagnostic agents, toxins, enzymes, antisense oligonucleotides and genes. Although sugar-containing delivery systems offer the possibility of improved delivery of the agent to the target when evaluated in vitro, some or most of the systems may not be effective in vivo. This is largely due to undesirable pharmacokinetic properties; for example, a highly potent antibody can bind to its antigen only when it reaches the site where the antigen is located. Therefore, in the development of cell-specific targeting system, the tissue distribution characteristics should be evaluated in vivo in order to investigate the various obstacles to targeted delivery such as limited passage through the endothelium, extensive uptake by mononuclear phagocyte system and rapid loss by glomerular filtration. Here, I will discuss how to develop cell-specific drug and gene targeting systems for liver cells, such as hepatocytes and liver nonparenchymal cells (Fig. 1), based on the pharmacokinetic analysis of the tissue distribution of macromolecular compounds. Then, I shall review the targeted delivery of various compounds to cells, aiming at the prevention of ischemia/ reperfusion injury, inhibition of tumor metastasis and gene therapy.

\section{PHARMACOKINETIC CONSIDERATIONS INVOLVING CELL-SPECIFIC TARGETING SYSTEMS USING GLY- COSYLATED PROTEINS}

The rational design of carbohydrate receptor-mediated cell-specific targeting systems can be achieved through an understanding of the molecular mechanism governing the interaction between the receptors and ligands. The interaction of galactosylated ligands with asialoglycoprotein receptors 


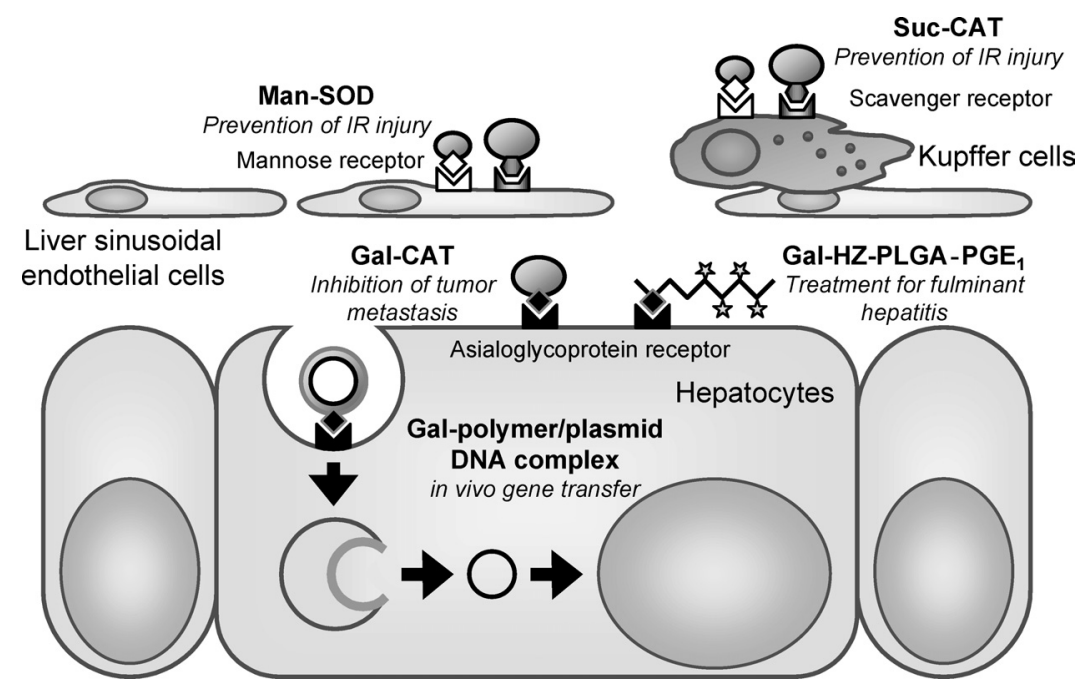

Fig. 1. Receptor-Mediated Cell-Specific Targeting of Drugs and Genes to Liver Cells

has been extensively investigated using isolated hepatocytes. Connolly et al. reported that highly clustered (branched) galactosides were more potent inhibitors than less clustered ones in their studies of the binding of ${ }^{125} \mathrm{I}$-asialoorosomucoid to hepatocytes. ${ }^{4)}$ The importance of a precise geometry of the sugar chains was suggested using multi-antennary oligosaccharides. ${ }^{5,6)}$ In order to modify proteins as well as other polymers with sugar moieties, monomeric sugar derivatives are suitable because they can be easily synthesized. Experiments using mannosylated bovine serum albumin (Man-BSA) ${ }^{7)}$ and galactosylated BSA (Gal-BSA) ${ }^{8}$ suggest that the number of sugar residues play an important role in recognition by macrophage mannose receptors or asialoglycoprotein receptors, respectively. However, the information obtained in these studies is not sufficient to design efficient targeting systems.

In addition to the affinity for the corresponding receptors, which is the major factor determining ligand-receptor interactions in vitro, additional factors such as blood flow rate, capillary structure and interaction with blood components ${ }^{9)}$ will affect the overall interaction with receptors in vivo. In the theoretical design of hepatocyte-targeted delivery systems, we have developed galactosylated proteins having different molecular weights and different numbers of galactose units, and investigated their tissue distribution in mice and rats. ${ }^{10-13)}$ During the modification procedures, attention was paid not to alter the electric charge of the proteins, because reduction in the charge sometimes increases the affinity of the protein for scavenger receptors. ${ }^{14)}$ In addition, a residualizing radiolabel using ${ }^{111}$ In was used for tracing glycosylated proteins after administration, and this resulted in only minor efflux of radioactivity from tissues taking up the labeled compounds. ${ }^{15-17)}$

After intravenous injection into mice, ${ }^{111}$ In-galactosylated proteins rapidly disappeared from the plasma. They were recovered in the liver in amounts that were highly dependent on the degree of galactose modification and the administered dose. Then, the time-courses of the plasma concentration and liver accumulation of the ${ }^{111}$ In-labeled galactosylated proteins were analyzed based on a physiological pharmacokinetic model, in which the body is represented by three compartments: plasma pool, the sinusoidal and Disse spaces in the liver, and the intracellular space in the liver. ${ }^{10,12)}$ The uptake of galactosylated protein in the liver was expressed as a saturable process with Michaelis-Menten kinetics having a maximum rate of uptake, $V_{\max , 1}(\mathrm{nmol} / \mathrm{h})$, and a Michaelis constant, $K_{\mathrm{m}, 1}(\mathrm{~nm})$. To estimate the pharmacokinetic parameters, differential equations derived from the model were simultaneously fitted to the experimental data of the plasma concentrations and liver accumulation of ${ }^{111}$ In-labeled galactosylated proteins using the non-linear least-squares method MULTI associated with the Runge-Kutta-Gill method. The Michaelis constant for the hepatic uptake of ${ }^{111}$ In-galactosylated recombinant human superoxide dismutase (Gal-SOD) was observed to be inversely correlated with the number of galactose residues, without a significant change in the maximum rate of uptake, $V_{\max , 1}$. This relationship could be successfully applied to other galactosylated proteins by using the surface density of the galactose residues as the degree of galactosylation (Fig. 2A), suggesting that this parameter controls the affinity of galactosylated proteins for asialoglycoprotein receptors. These analyses clearly demonstrated that an efficient delivery of proteins to hepatocytes by galactosylation can be achieved by adjusting the degree of galactosylation to a value for the distance between two vicinal galactose residues as short as $20-30 \AA$, which is of the same order as the naturally occurring sugar clusters arranged at the vertices of a triangle with sides of dimensions 15,22 , and $25 \AA$. .)

A similar pharmacokinetic analysis was applied to the tissue distribution of mannosylated proteins. ${ }^{18,19)}$ We found that mannosylated proteins bind to serum-type mannan binding protein (MBP) in a structure-dependent manner. The binding to MBP was obvious at low concentrations of mannosylated proteins, and the disappearance from plasma was greatly retarded at doses less than $1 \mathrm{mg} / \mathrm{kg}$ when the molecular weight of the mannosylated proteins was 67000 or greater. Because ${ }^{111}$ In-Man-BSA showed capacity-limited plasma protein binding, this binding with a maximum binding concentration $\left(B_{\max } ; \mathrm{nM}\right)$ and a dissociation constant $\left(K_{\mathrm{d}} ; \mathrm{nm}\right)$ was included in the physiological model for the analysis of the tissue distribution of ${ }^{111}$ In-Man-BSA. ${ }^{19)}$ As shown in Figs. 2B, C, the $K_{\mathrm{m}, 1}$ values were fairly similar $(34-68 \mathrm{~nm})$ except for ${ }^{111} \mathrm{In}$ $\operatorname{Man}_{12}$-BSA (300 nM), whereas the $K_{\mathrm{d}}$ decreased dramatically 

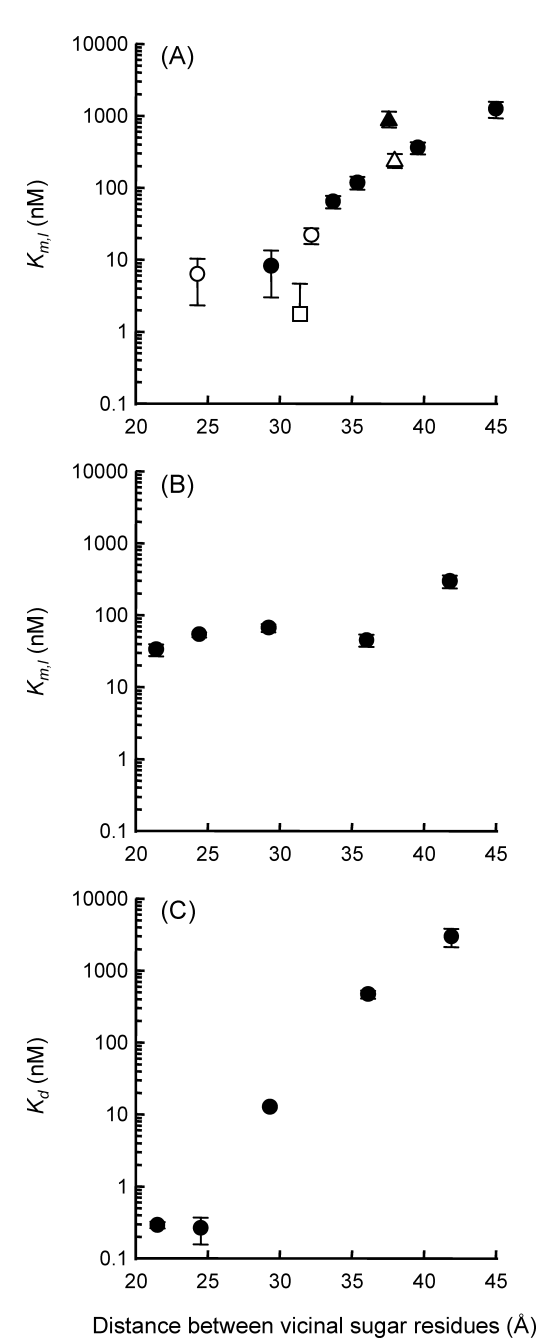

Fig. 2. Relationship between Pharmacokinetic Parameters and the Degree of Modification of ${ }^{111}$ In-Glycosylated Proteins

(A) $K_{\mathrm{m}, \mathrm{l}}$ of ${ }^{111}$ In-Gal-immunoglobulin G ( $\square$ ), Gal-BSA (O), Gal-SOD (•), Gal-soybean trypsin inhibitor $(\triangle)$, and Gal-chicken egg white lysozyme $(\mathbf{\Lambda})$. (B) $K_{\mathrm{m}, 1}$ and $(\mathrm{C})$ $K_{\mathrm{d}}$ of ${ }^{111}$ In-Man-BSA. Each parameter was plotted as the mean \pm S.D. against the average distance of two vicinal sugar residues.

on increasing the number or density of the mannose residues from $3000 \mathrm{~nm}$ for ${ }^{111} \mathrm{In} \mathrm{Man}_{12}$-BSA to $0.27-0.3 \mathrm{nM}$ for ${ }^{111} \mathrm{In}$ -

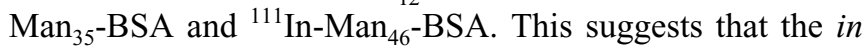
vivo recognition of $\mathrm{MBP}$ has a stronger cluster effect than that of mannose receptors. In addition, the relationship between the density of mannose and the $K_{\mathrm{d}}$ (Fig. 2C) was comparable to that between the density of galactose on galactosylated proteins and the $K_{\mathrm{m}, 1}$ (Fig. 2A). The differences in the recognition of mannosylated ligands by hepatic mannose receptors and serum MBP could be explained by the fact that the mannose receptors contain different multiple carbohydrate recognition domains (CRDs) in the single polypeptide, whereas MBP is composed of six or more monomers with only a single CRD. ${ }^{20)}$ These findings will prove useful not only for designing cell-specific targeting systems for liver nonparenchymal cells but also for understanding the physiological roles of these lectins in the host defense system.
GLYCOSYLATED POLYMERS AS NOVEL DRUG/GENE CARRIERS

Polymers with multiple sites for conjugation with sugars as well as drugs can be more versatile carriers for drugs and genes than glycosylated proteins. Therefore, we have developed glycosylated polymers and examined their tissue distribution characteristics in mice. ${ }^{21-24)}$ In these studies, carboxymethyl-dextran, poly-L-glutamic acid (PLGA) and polyL-lysine (PLL) were modified with galactose or mannose to obtain cell-specific targeting systems. A good correlation between the apparent hepatic uptake clearance of galactosylated PLGA (Gal-PLGA) and the number of galactose residues per PLGA was observed, ${ }^{23)}$ suggesting that the rate and extent of the delivery can be controlled by the number of galactose units as observed with galactosylated proteins. However, when the hepatic targeting of Gal-PLGA was compared with galactosylated proteins using the clearance values and the estimated surface density of galactose, it was found that Gal-PLGA requires more galactose residues to be recognized by asialoglycoprotein receptors than galactosylated proteins. ${ }^{25}$ Cationic PLL derivatives accumulated in the liver irrespective of the modification with galactose or mannose, because of the charge-mediated interaction with both parenchymal and nonparenchymal cells in the liver. ${ }^{24)}$ However, pharmacokinetic analyses indicated that the hepatic uptake clearance of PLL increased when the polymer was modified with galactose or mannose.

Glycosylated polymers have been used for the targeted delivery of low-molecular-weight drugs and nucleotides. ${ }^{25-28)}$ Targeted delivery of vitamin $\mathrm{K}_{5}$ by conjugating it with GalPLGA resulted in a rapid and continuous antihemorrhagic activity. Prostaglandin $\mathrm{E}_{1}\left(\mathrm{PGE}_{1}\right)$ was also successfully delivered to hepatocytes following its conjugation to Gal-PLGA hydrazide (Gal-HZ-PLGA) via a hydrazone bond. This targeting effectively inhibited the increase in plasma transaminase activity in the mouse model of fulminant hepatitis. ${ }^{26)}$

\section{TARGETED DELIVERY OF ANTIOXIDANT ENZYMES BY DIRECT GLYCOSYLATION: PREVENTION OF IS- CHEMIA/REPERFUSION INJURY}

Biologically active proteins are candidates for a variety of diseases and disorders, but most proteins have failed to exhibit any therapeutic benefits due mainly to problems associated with their pharmacokinetic properties. For instance, SOD, an antioxidant enzyme degrading superoxide anion, was regarded as a potential therapeutic agent for reactive oxygen species (ROS)-mediated diseases such as rheumatoid arthritis; however, it is rapidly cleared by glomerular filtration in the kidney, leading to a plasma elimination half-life of only 5-10 min following intravenous injection in rodents. Catalase detoxifying hydrogen peroxide, the metabolite of the superoxide anion, is also rapidly cleared by hepatocytes after intravenous injection. ${ }^{29)}$ Effective applications of these antioxidant enzymes to ROS-mediated injuries, therefore, can be achieved by their targeted delivery to sites where ROS are generated.

Ischemia/reperfusion injury is widely recognized as a significant source of morbidity and mortality in a number of clinical disorders including myocardial infarction. ${ }^{30)}$ In addi- 
tion, this injury is one of the main causes of the initial poor liver function after liver transplantation. Because many of the injury-induced pathophysiological events are mediated through the production of ROS, targeted delivery of antioxidant enzymes could be useful in the treatment of various ischemia/reperfusion injuries.

The local hepatic injury associated with ischemia/reperfusion is considered to involve two phases, ${ }^{31)}$ with the initial injury being mediated by activated Kupffer cells and the subsequent injury being mediated by neutrophils that are primed during the initial period. We have tried to apply glycosylation methods as well as succinylation ${ }^{32)}$ to the delivery of SOD and catalase to the liver in a cell-specific manner, aiming at preventing hepatic ischemia/reperfusion injury. ${ }^{29,33-37)}$ Galactosylated and mannosylated derivatives of SOD and catalase have been successfully developed with enzymatic activities of $90 \%$ or higher. In addition, succinylated catalase (Suc-CAT) was also synthesized as a catalase to target liver sinusoidal endothelial cells through a scavenger receptor-mediated process. Although the ischemia following reperfusion resulted in a striking increase in serum transaminase activity, the administration of SOD and catalase derivatives significantly inhibited this. Among various combinations, Suc-CAT and Man-SOD showed the greatest inhibitory effect against the injury evaluated by serum transaminase activity and by the integrity of the liver tissues. ${ }^{36)}$ This combination also significantly suppressed the expression of intercellular adhesion molecule-1 along the hepatic sinusoids and prevented neutrophil infiltration in the liver. ${ }^{37)}$ The numbers of mannose receptors and scavenger receptors and the affinity of these derivatives for the receptors suggest that the liver sinusoidal endothelial cells have a higher level of catalase activity than SOD activity, whereas Kupffer cells have mainly SOD activity. Therefore, a plausible mechanism of the protection by Suc-CAT and Man-SOD is the dismutation of superoxide anion that Kupffer cells generate by Man-SOD, followed by Suc-CAT-mediated elimination of hydrogen peroxide, which is a stable amphiphilic molecule that can diffuse through the cellular membrane. Thus, this 'double targeting' of SOD and catalase to liver nonparenchymal cells appears to be a promising approach to reducing the ROS produced by Kupffer cells and neutrophils infiltrating tissue.

\section{INHIBITION OF TUMOR METASTASIS BY TARGETED DELIVERY OF CATALASE}

Although high levels of ROS are cytotoxic, as indicated in hepatic ischemia/reperfusion injuries, low levels of ROS act as second messengers in the activation of cellular responses. It has been reported that ROS are involved in the regulation of the expression levels of adhesion molecules and matrix metalloproteinases (MMPs). ${ }^{38)}$ Furthermore, a low level of hydrogen peroxide increases cell proliferation. Therefore, detoxification of ROS, especially hydrogen peroxide, would be beneficial for the prevention of tumor metastasis. Some studies have already shown significant, but limited, effects of antioxidant enzymes on experimental tumor metastasis in animal models, ${ }^{39,40)}$ but no attempts have been made to achieve their targeted delivery.

Therefore, we examined the effects on tumor metastasis of targeted delivery of catalase to the liver and lung, two major sites of metastatic events. ${ }^{41-43)}$ An intraportal injection of $1 \times 10^{5}$ mouse colon carcinoma colon 26 cells resulted in the formation of more than 50 metastatic colonies on the surface of the liver at $14 \mathrm{~d}$ after injection. An intravenous injection of catalase (CAT; 35000 units/kg of body weight) significantly reduced the number of colonies in the liver. Among the catalase derivatives examined, Gal-CAT showed the greatest inhibitory effect on hepatic metastasis, and the number of colonies was significantly smaller than that following treatment with catalase, Man-CAT or Suc-CAT. ${ }^{42)}$ High activity of MMPs, especially MMP-9, were detected in the liver of mice bearing metastatic tumor tissues, and this was significantly reduced by Gal-CAT. The in situ zymography suggested that the gelatinase activities in the tumor-bearing liver were close to the sinusoids of the liver. In addition, the gelatin zymographic analysis of liver homogenates clearly demonstrated that MMP-9 is the major contributor to gelatinolysis in tumor-bearing mouse liver after intraportal inoculation of colon 26 tumor cells. Further studies are needed to identify which cells in the liver contribute to the gelatinase activity in tumor-bearing liver, because MMPs are known to be produced from various cells including tumor cells, endothelial cells, macrophages and hepatocytes. Our preliminary results obtained using cultured hepatocytes and colon 26 tumor cells show that, under oxidative stress, MMP-9 is largely produced by hepatocytes, whereas MMP-2 is from colon 26 cells. These findings suggest that hepatocytes are the major source of the MMPs detected in the liver, which supports the experimental data showing that Gal-CAT, the hepatocyte-targeting type, has the greatest inhibitory effect on tumor metastasis in the liver.

\section{APPLICATION OF CELL-SPECIFIC TARGETING SYS- TEMS TO NONVIRAL GENE DELIVERY}

The in vivo gene transfer profile required for effective gene therapy depends on the target disease. ${ }^{44)}$ Target cell-specific gene transfer is important for various aspects of in vivo gene therapy, because transgene expression in non-target cells could lead to the induction of side-effects. Generally speaking, plasmid DNA-based nonviral vectors offer the advantages of safety and versatility over viral vectors. ${ }^{45)}$ So far, several promising results of gene transfer using plasmid DNA-based approaches have been reported in preclinical and clinical settings. ${ }^{46)}$

Gene transfer is expected to occur in cells reached by vectors directly or via the blood circulation. To achieve target cell-specific gene transfer, a variety of approaches has been examined, from the selection of the administration route of the vector to the use of tissue-specific promoters. Among those, targeted delivery of plasmid DNA using a receptormediated process would be an ideal approach. Plasmid DNA is a huge macromolecule with a strong negative charge and, therefore, its tissue distribution is highly restricted (Fig. $3)^{45,47)}$ The uptake by Kupffer cells and liver sinusoidal endothelial cells via a scavenger receptor-like mechanism largely determines its tissue distribution following intravascular administration of plasmid DNA in its naked form. ${ }^{48,49)}$

Complex formation with positively charged molecules is an easy way to reduce the negative charge of plasmid DNA. We have synthesized a series of glycosylated polymers to 


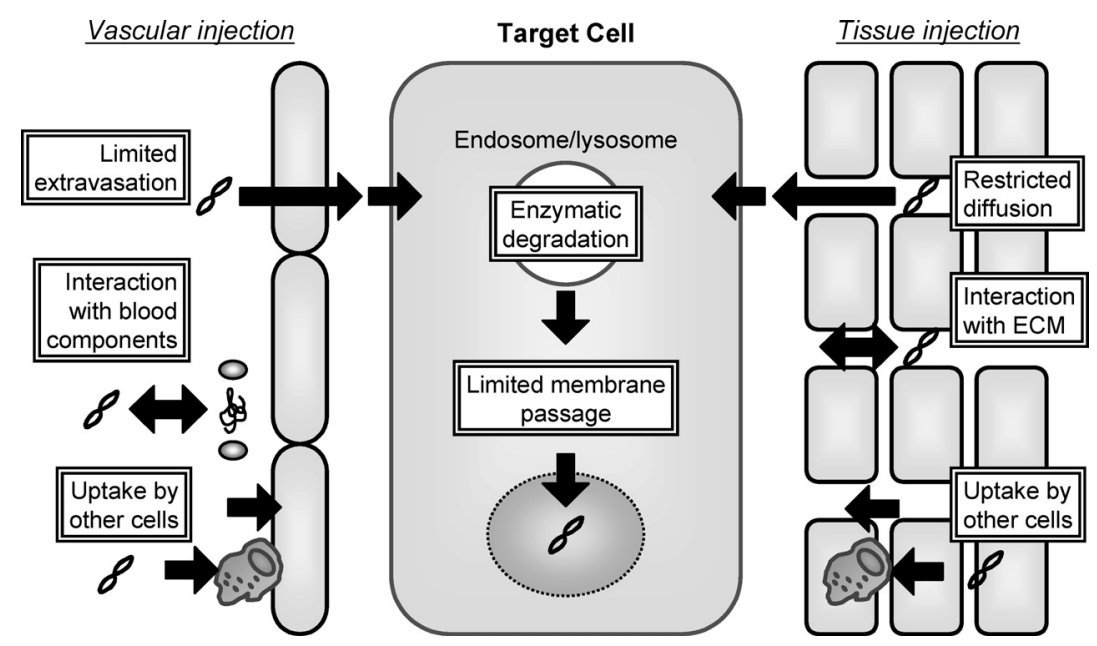

Fig. 3. Delivery Barriers for Nonviral Vector in Target Cell-Directed in Vivo Gene Transfer

achieve cell-specific gene transfer to carbohydrate receptorpositive cells. ${ }^{50-53)}$ Galactosylated PLL (Gal-PLL) synthesized using PLL with a molecular weight of 1800,13000 or 29000 was mixed with plasmid DNA to form complexes. ${ }^{50)}$ A larger amount of $\mathrm{PLL}_{1800}$ was required for complex formation than with $\mathrm{PLL}_{13000}$ and $\mathrm{PLL}_{29000}$, and increasing the number of galactose units on Gal-PLL resulted in reduced binding to plasmid DNA. The particle size and zeta-potential of the complexes varied depending on the mixing ratio and Gal-PLL used, and plasmid DNA/Gal-PLL complexes having diameters of $200 \mathrm{~nm}$ or less and a weak negative charge were prepared. After intravenous injection of ${ }^{32} \mathrm{P}$-plasmid $\mathrm{DNA} / \mathrm{Gal}_{13}-\mathrm{PLL}_{13000}$ and ${ }^{32} \mathrm{P}$-plasmid DNA/ $\mathrm{Gal}_{26}-\mathrm{PLL}_{29000}$, almost $80 \%$ of the radioactivity rapidly accumulated in the liver, preferentially in hepatocytes. Compared with these complexes, ${ }^{32} \mathrm{P}$-plasmid DNA/Gal $-\mathrm{PLL}_{1800}$ and ${ }^{32} \mathrm{P}$-plasmid $\mathrm{DNA} / \mathrm{Gal}_{5}-\mathrm{PLL}_{13000}$ had a smaller hepatic clearance, suggesting that both the molecular weight of PLL and the degree of galactose modification determine the hepatic targeting of plasmid DNA. In vitro and in vivo gene expression studies showed that plasmid $\mathrm{DNA} / \mathrm{Gal}_{13}-\mathrm{PLL}_{13000}$ and plasmid DNA/ $\mathrm{Gal}_{26}-\mathrm{PLL}_{29000}$ complexes were superior to plasmid DNA/ $\mathrm{Gal}_{5}-\mathrm{PLL}_{1800}$ complex for introducing the DNA into cells. Thus, targeted delivery of plasmid DNA to hepatocytes in vivo was successfully carried out by controlling both the physicochemical properties of the carrier, Gal-PLL, and the particulate properties of the plasmid DNA/Gal-PLL complexes. The results obtained clearly indicate that the molecular weight and degree of galactose modification of Gal-PLL are major factors determining the stability of DNA/carrier complex formation; this in turn determines the cell-specific targeting and transgene efficiency.

However, the level of transgene expression by targeted gene delivery does not appear to be sufficient for treating diseases. To increase the expression efficiency by a nonviral approach, compounds that can enhance transgene expression, such as viruses or viral proteins, fusogenic lipids, and fusogenic, and membrane-disruptive peptides have been introduced into nonviral carrier systems. To preserve the advantages of nonviral systems, only synthetic compounds like fusogenic peptides are candidate helper molecules. In addition, from a pharmacokinetic point of view, they should be firmly attached to the delivery system. Based on these criteria, we have tried to improve the efficiency of transgene expression by synthesizing a multi-functional carrier molecule, galactosylated poly-L-ornithine (pOrn)-fusogenic peptide conjugate. ${ }^{51)}$ This molecule was designed so that it would (i) bind and condense DNA to optimize the systemic disposition profile, (ii) deliver DNA to hepatocytes through asialoglycoprotein receptor recognition, and (iii) release DNA from endosomes/lysosomes into cytoplasm after internalization. To this end, a cationic pOrn was modified first with galactose, then with a fusogenic peptide (mHA2) to obtain Gal-pOrn-mHA2. When applied with Gal-pOrn-mHA2 to HepG2 cells, an asialoglycoprotein receptor-positive cell line, fluorescein-labeled plasmid DNA showed a diffuse profile, suggesting the release of plasmid DNA from the endosome/lysosome compartment. A large amount of transgene product was obtained in the liver of mice injected with plasmid DNA/Gal-pOrnmHA2 complex, which was much greater than that obtained with plasmid DNA/Gal-pOrn or plasmid DNA/cationic liposome complex. The luciferase activity in hepatocytes accounted for more than $95 \%$ of the total activity in all the tissues examined. Thus, hepatocyte-targeted in vivo gene expression was achieved by the intravenous injection of DNA complex with the multi-functional gene carrier, which can be an effective therapeutic option for hepatic diseases in which any important genes in hepatocytes are missing or mutated. ${ }^{54)}$

\section{CONCLUSION}

Cell-specific targeting of drugs and genes is a promising approach not only for increasing the therapeutic benefits but also for reducing the side-effects. Galactosylation and mannosylation of macromolecules have been proved to be effective in delivering a variety of pharmaceuticals from low-molecular-weight drugs such as $\mathrm{PGE}_{1}$ to huge plasmid DNA. Careful examination of the tissue distribution of such delivery systems after in vivo administration is essential for the theoretical development of effective delivery systems, because there are many delivery barriers especially for nonviral vectors. ${ }^{45)}$ Therefore, analytical methods for the tissue distribution of macromolecular compounds are also important for the design of cell-specific targeting systems. We recently de- 
veloped a novel radiolabeling method for plasmid DNA that is suitable for the analysis of the tissue distribution of plasmid DNA and its complexes. ${ }^{55)}$ Finally, it is fully expected that further basic studies on cell-specific targeting will lead to applications in routine medical practice in the near future.

Acknowledgements The author is very grateful to Professors Hitoshi Sezaki, Mitsuru Hashida and Yoshinobu Takakura for their help and guidance, and would like also to thank many collaborators for their help in pursuing these studies. This work is supported in part by Grants-in-Aid for Scientific Research from the Ministry of Education, Culture, Sports, Science and Technology of Japan and by grants from the Ministry of Health, Labour and Welfare of Japan.

\section{REFERENCES}

1) Ringsdorf H., J. Polym. Sci.: Polym. Symp., 51, 135-153 (1975).

2) Ashwell G., Harford J., Ann. Rev. Biochem., 51, 531-554 (1982).

$3)$ Rogers J. C., Kornfeld S., Biochem. Biophys. Res. Commun., 45 $622-629(1971)$

4) Connolly D. T., Townsend R. R., Kawaguchi K., Bell W. R., Lee Y. C., J. Biol. Chem., 257, 939-945 (1982).

5) Lee Y. C., Townsend R. R., Hardy M. R., Lonngren J., Arnarp J., Haraldsson M., Lonn H., J. Biol. Chem., 258, 199-202 (1983).

6) Townsend R. R., Hardy M. R., Wong T. C., Lee Y. C., Biochemistry, 25, 5716-5725 (1986).

7) Hoppe C. A., Lee Y. C., J. Biol. Chem., 258, 14193-14199 (1983).

8) Vera D. R., Krohn K. A., Stadalnik R. C., Scheibe P. O., J. Nucl. Med., 25, 779-787 (1984).

9) Opanasopit P., Nishikawa M., Hashida M., Crit. Rev. Ther. Drug Carrier Syst., 19, 191-233 (2002).

10) Nishikawa M., Ohtsubo Y., Ohno J., Fujita T., Koyama Y., Takakura Y., Hashida M., Sezaki H., Int. J. Pharm., 85, 75-85 (1992).

11) Nishikawa M., Hirabayashi H., Takakura Y., Hashida M., Pharm. Res., 12, 209-214 (1995).

12) Nishikawa M., Miyazaki C., Yamashita F., Takakura Y., Hashida M., Am. J. Physiol., 268, G849-G856 (1995).

13) Ogawara K., Nishikawa M., Takakura Y., Hashida M., J. Control. Release, 50, 309-317 (1998).

14) Jansen R. W., Molema G., Ching T. L., Oosting R., Harms G., Moolenaar F., Hardonk M. J., Meijer D. K. F., J. Biol. Chem., 266, 33433348 (1991).

15) Nishikawa M., Staud F., Takemura S., Takakura Y., Hashida M., Biol. Pharm. Bull., 22, 214-218 (1999).

16) Staud F., Nishikawa M., Morimoto K., Takakura Y., Hashida M., J. Pharm. Sci., 88, 577-585 (1999).

17) Nishikawa M., Takakura Y., Hashida M., Adv. Drug Deliv. Rev., 21, 135-155 (1996).

18) Ogawara K., Hasegawa S., Nishikawa M., Takakura Y., Hashida M., J. Drug Target., 6, 349-360 (1999).

19) Opanasopit P., Shiraishi K., Nishikawa M., Yamashita F., Takakura Y., Hashida M., Am. J. Physiol., 280, G879—G889 (2001).

20) Weis W. I., Taylor M. E., Drickamer K., Immunol. Rev., 163, 19-34 (1998).

21) Nishikawa M., Yamashita F., Takakura Y., Hashida M., Sezaki H., J. Pharm. Pharmacol., 44, 396-401 (1992).

22) Nishikawa M., Kamijo A., Fujita T., Takakura Y., Sezaki H., Hashida M., Pharm. Res., 10, 1253-1261 (1993).

23) Hirabayashi H., Nishikawa M., Takakura Y., Hashida M., Pharm. Res., 13, 880-884 (1996).

24) Akamatsu K., Imai M., Yamasaki Y., Nishikawa M., Takakura Y.,
Hashida M., J. Drug Target., 6, 229-239 (1998).

25) Hashida M., Hirabayashi H., Nishikawa M., Takakura Y., J. Control. Release, 46, 129-137 (1997).

26) Akamatsu K., Yamasaki Y., Nishikawa M., Takakura Y., Hashida M., J. Pharmacol. Exp. Ther, 290, 1242-1249 (1999).

27) Akamatsu K., Yamasaki Y., Nishikawa M., Takakura Y., Hashida M., Biochem. Pharmacol., 62, 1531-1536 (2001).

28) Mahato R. I., Takemura S., Akamatsu K., Nishikawa M., Takakura Y., Hashida M., Biochem. Pharmacol., 53, 887-895 (1997).

29) Yabe Y., Koyama Y., Nishikawa M., Takakura Y., Hashida M., Free Radic. Res., 30, 265-274 (1999).

30) Szabo A., Heemann U., Transplant. Proc., 30, $4281-4284$ (1998).

31) Jaeschke H., Bautista A. P., Spolarics Z., Spitzer J. J., Free Radic. Res. Commun., 15, 277-284 (1991).

32) Yamasaki Y., Sumimoto K., Nishikawa M., Yamashita F., Yamaoka K., Hashida M., Takakura Y., J. Pharmacol. Exp. Ther, 301, 467-477 (2002).

33) Fujita T., Nishikawa M., Tamaki C., Takakura Y., Hashida M., Sezaki H., J. Pharmacol. Exp. Ther., 263, 971-978 (1992).

34) Fujita T., Furitsu H., Nishikawa M., Takakura Y., Sezaki H., Hashida M., Biochem. Biophys. Res. Commun., 189, 191-196 (1992).

35) Yabe Y., Nishikawa M., Tamada A., Takakura Y., Hashida M., J. Pharmacol. Exp. Ther., 289, 1176-1184 (1999).

36) Yabe Y., Kobayashi N., Nishihashi T., Takahashi R., Nishikawa M., Takakura Y., Hashida M., J. Pharmacol. Exp. Ther., 298, 894-899 (2001).

37) Yabe Y., Kobayashi N., Nishikawa M., Mihara K., Yamashita F., Takakura Y., Hashida M., Pharm. Res., 19, 1815-1821 (2002).

38) Tang D. G., Honn K. V., Invasion Metastasis, 14, 109-122 (1994).

39) Nonaka Y., Iwagaki H., Kimura T., Fuchimoto S., Orita K., Int. J. Cancer, 54, 983-986 (1993).

40) Yoshizaki N., Mogi Y., Muramatsu H., Koike K., Kogawa K., Niitsu Y., Int. J. Cancer, 57, 287-292 (1994).

41) Nishikawa M., Tamada A., Kumai H., Yamashita F., Hashida M., Int. J. Cancer, 99, 474-479 (2002).

42) Nishikawa M., Tamada A., Hyoudou K., Umeyama Y., Takahashi Y., Kobayashi Y., Kumai H., Ishida E., Staud F., Yabe Y., Takakura Y., Yamashita F., Hashida M., Clin. Exp. Metastasis, 21, 213-221 (2004).

43) Hyoudou K., Nishikawa M., Umeyama Y., Kobayashi Y., Yamashita F., Hashida M., Clin. Cancer Res., 10, 7685-7691 (2004).

44) Nishikawa M., Hashida M., Biol. Pharm. Bull., 25, 275-283 (2002).

45) Nishikawa M., Huang L., Hum. Gene Ther., 12, 861-870 (2001).

46) Morishita R., Aoki M., Hashiya N., Makino H., Yamasaki K., Azuma J., Sawa Y., Matsuda H., Kaneda Y., Ogihara T., Hypertension, 44, 203-209 (2004).

47) Kobayashi N., Nishikawa M., Takakura Y., "Drug Delivery: Principles and Applications," ed. by Wang B., Siahaan T., Soltero R., John Wiley \& Sons, Inc., Hoboken, NJ, 2005.

48) Kawabata K., Takakura Y., Hashida M., Pharm. Res., 12, 825-830 (1995).

49) Hisazumi J., Kobayashi N., Nishikawa M., Takakura Y., Pharm. Res., 21, 1223-1228 (2004).

50) Nishikawa M., Takemura S., Takakura Y., Hashida M., J. Pharmacol. Exp. Ther, 287, 408-415 (1998).

51) Nishikawa M., Yamauchi M., Morimoto K., Ishida E., Takakura Y., Hashida M., Gene Ther., 7, 548-555 (2000).

52) Nishikawa M., Takemura S., Yamashita F., Takakura Y., Meijer D. K., Hashida M., Swart P. J., J. Drug Target., 8, 29-38 (2000).

53) Morimoto K., Nishikawa M., Kawakami S., Nakano T., Hattori Y., Fumoto S., Yamashita F., Hashida M., Mol. Ther., 7, 254-261 (2003).

54) Kren B. T., Metz R., Kumar R., Steer C. J., Seminars Liver Dis., 19, 93-104 (1999).

55) Nishikawa M., Nakano T., Okabe T., Hamaguchi N., Yamasaki Y., Takakura Y., Yamashita F., Hashida M., Bioconjug. Chem., 14, 955961 (2003). 